\title{
Rectal Adenoma
}

National Cancer Institute

\section{Source}

National Cancer Institute. Rectal Adenoma. NCI Thesaurus. Code C5546.

An adenoma that arises from the rectum. The group of rectal adenomas includes

tubular, villous, and tubulovillous adenomas, traditional serrated adenomas, sessile serrated adenomas/polyps, and familial adenomatous polyposis. 